\title{
Cross-Exercise on Quadriceps Deficit after ACL Reconstruction
}

\author{
Maria Papandreou, Ph.D. ${ }^{1}$ Evdokia Billis, Ph.D. ${ }^{2}$ George Papathanasiou, Ph.D. ${ }^{1}$ \\ Panagiotis Spyropoulos, Ph.D. ${ }^{1}$ Nikos Papaioannou, Ph.D. ${ }^{3}$
}

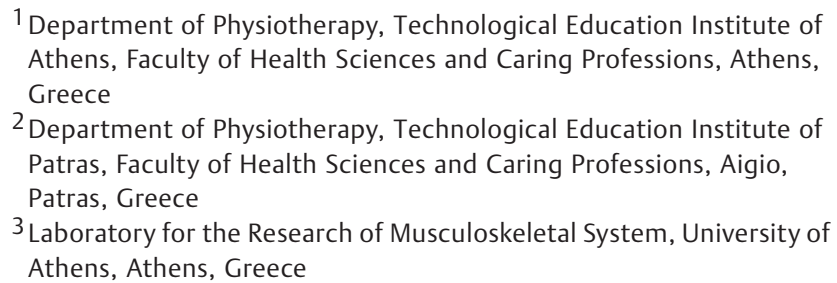

Address for correspondence and reprint requests Maria Papandreou, Ph.D., Lecturer in Physiotherapy, 9 Poseidonos Avenue, Marathonas 19007, Greece (e-mail: mpapand@teiath.gr).

J Knee Surg 2013;26:51-58.
Following anterior cruciate ligament (ACL) surgery significant quadriceps muscle strength deficit (QD) usually for up to $20 \%$ compared with the uninjured knee in the first 4 weeks has been reported. ${ }^{1-4}$ And, preoperative quadriceps strength (QS) has been found as one of the important predictors for knee function for as long as 2 years after ACL reconstruction. ${ }^{5-7}$ However, so far, there is no agreement as to what is the ideal treatment for postoperative quadriceps weakness for individuals after ACL reconstruction.

received

February 23, 2011

accepted after revision

January 22, 2012

published online

May 15, 2012

Quadriceps muscle activity causes anterior tibia translation between 20 and 60 degrees of knee flexion ${ }^{8,9}$ and this is closely related to the increased ACL strain levels at these angles. ${ }^{10-12}$ Thus, the fact that $\mathrm{QD}$ is greater at the knee range of 60 degrees ${ }^{10-13}$ following ACL reconstruction, might be attributed to the interrelation between quadriceps activity and ACL strain levels following the operation graft technique. These findings seem to justify the specific focus of the exercise rehabilitation program at 60 degrees of motion, in the early

Copyright $\odot 2013$ by Thieme Medical Publishers, Inc., 333 Seventh Avenue, New York, NY 10001, USA. Tel: +1(212) 584-4662.
DOI http://dx.doi.org/ 10.1055/s-0032-1313744. ISSN 1538-8506. 
stage after ACL reconstruction. ${ }^{10-13}$ As a consequence, for ACL-reconstructed patients an optimizing postoperative rehabilitation program for alleviating QD, through the safest and most expeditious means available is recommendable. Such a safe, practical, economic, and potentially beneficial form of exercise is contralateral or cross-exercise (CE).

$\mathrm{CE}$ focus on exercising the contralateral limb to increase the strength in the homologous muscle on the untrained limb, without directly involving the latter in the motor activity. ${ }^{14} \mathrm{CE}$ is a safe form of exercise, because exercise of one limb can produce a beneficial effect in the contralateral limb for patients who have conditions that prevent them from exercising a limb. ${ }^{14}$

However, the clinical significance of this intervention has not been critically evaluated for special population groups such as, postoperative patients versus unexercised control groups.

Thus, it is not unreasonable to assume that cross-eccentric exercise (CEE) applied at a higher than 3 days per week frequency (such as 5 days) as an adjunct to the traditional ACL rehabilitation program may improve $Q D$ at 60 degrees on ACL-reconstructed knee in the early ACL-postoperative stage.

The goals of our study were to explore (1) the effects of an 8-week CEE program on QD at 60 degrees of flexion on ACLreconstructed knees and (2) any changes in QD when applying CEE for 3 or 5 times per week in the early stage of ACL reconstruction.

\section{Methods}

This study received ethical approval from the Committee of Laboratory for Research of Musculoskeletal system at the University of Athens.

\section{Sample}

Participants consisted of male patient soldiers in the Greek army referred from the outpatient Orthopaedic and Physical Therapy department of General Army Hospital 401 (GAH 401) in Athens, with unilateral ACL ruptures confirmed by both magnetic resonance and clinical examination performed by the same orthopedic surgeon.

Out of the 58 patients initially assessed, 42 met the inclusion criteria for eligibility in the study, and were randomly assigned (by flip coin) into one of three groups, two experimental ones (Groups A and B) and one control (Group C).

Our sampling selection is included in stratified random sampling. A power analysis performed before the study and 14 subjects comprised each one of the three groups. Patients' characteristics and admission profiles are illustrated in -Table 1.

To be considered eligible for inclusion patients had to: (1) be between 20 and 25 years of age, (2) have a complete rupture of ACL within the past 40 days to 6 months (subacute phase of ACL injury) ${ }^{15,16}$ with no other recent or previous injuries that demanded surgical reconstruction, (3) have at least $3 \mathrm{~mm}$ of bilateral difference in anterior knee joint laxity, as measured by KT1000 knee arthrometer (MEDmetric, San
Diego, CA), (4) be between levels C and D in the objective part of 2000 International Knee Documentation Committee ${ }^{17}$ knee examination form (surgical part), indicating abnormal or severely abnormal knee function, and (5) score between 0 and 5 in activity levels in recreational or sports activities as assessed by Tegner activity score questionnaire ( $\mathbf{- T a b l e ~} \mathbf{1}){ }^{18}$

Patients were excluded if they had clinical varus/valgus laxity or symptomatic meniscal injuries, painful knee active range of motion, joint swelling, leg length discrepancy, cartilage lesions affecting the subchondral bone, fractures, and a history of lower extremity pain in the last 6 months that did not agree with the ACL-rehabilitation requirements.

An arthroscopically assisted autograft technique was used by the same surgeon, using the semitendinosus and gracilis tendons in quadrapted fashion as a graft source. ${ }^{19}$ Before inclusion, all patients signed a written informed consent form.

\section{Outcome Measure}

All patients were evaluated in two phases; 1 week preoperatively and 9 weeks postoperatively.

QS was tested with isokinetic dynamometer (Kin Com $\mathrm{AT}^{+}$, Chattanooga Group Inc., Chattanooga, TN) by performing three maximum isometric contractions of 5 seconds each at 60 degrees of knee flexion at each knee. Patients performed four repetitions as a practice trial before testing. The uninjured knee was tested first and was followed by the ACLinjured one. Visual and verbal encouragement was provided. Isokinetic peak torque values were measured in Newton meters $(\mathrm{Nm})$ for both limbs at 60-degree knee flexion angle.

Leg dominance was assessed on the basis of a questionnaire consisting of six questions specifically selected from the literature as highly reliable. ${ }^{20,21}$ of the 42 participants, 12 were left-leg dominant, 8 had equally dominant sides, and 22 were right-leg dominant (-Table $\mathbf{1}$ ).

\section{ACL Rehabilitation Program}

All subjects commenced the ACL rehabilitation program 1 week following reconstruction at a 5-day weekly frequency (Monday to Friday) for 8 weeks.

All subjects received the same ACL rehabilitation program, which was divided into two subsequent phases; the progressive 8 -week program corresponded to phase 2 according to Wilk et $\mathrm{al}^{22}$ and Majima et $\mathrm{al}^{23}$ rehabilitation principles (-Table 2).

The 8-week time interval for rehabilitation was considered appropriate and adequate for resolving knee impairments (swelling pain), range of motion deficits, restoring muscle strength, and neuromuscular responses. Additionally, the 8 -week duration is related to the graft vascularization phase ${ }^{24-26}$ as well as specific biochemical, mitochondrial, and neurological muscular adaptations to take place. ${ }^{1,3}$

Consequently, we hypothesized that this duration could be critical in establishing a strength stimulus on QD after ACL reconstruction. The program was delivered by two highly experienced musculoskeletal physical therapists of the Physiotherapy Department of $401 \mathrm{GAH}$ (mean musculoskeletal experience: 5 years). 
Table 1 Subjects' Characteristics and Admission Criteria (Mean \pm SD)

\begin{tabular}{|l|l|l|l|}
\hline Subjects Characteristics & Group A (3 d/wk) $(\boldsymbol{n}=14)$ & Group B (5 d/wk) $(\boldsymbol{n}=14)$ & Group C (Control) $(\boldsymbol{n}=14)$ \\
\hline Age $(\mathrm{y})$ & $23.64 \pm 2.56$ & $25.07 \pm 2.40$ & $23.14 \pm 2.71$ \\
\hline Weight $(\mathrm{kg})$ & $81.28 \pm 8.40$ & $82.50 \pm 9.83$ & $75.00 \pm 8$ \\
\hline Height $(\mathrm{cm})$ & $179.07 \pm 5.18$ & $182.21 \pm 4.70$ & $175.85 \pm 5.78$ \\
\hline BMI $\left(\mathrm{kg} / \mathrm{m}^{2}\right)$ & $24.80 \pm 2.20$ & $25.24 \pm 2.90$ & $25.80 \pm 4.73$ \\
\hline Time of ACL injury (months) & $4.42 \pm 1.79$ & $4.42 \pm 1.75$ & $3.67 \pm 1.78$ \\
\hline SD (KT-1000) (mm) & $5.57 \pm 2.40$ & $6.35 \pm 1.21$ & $5.92 \pm 2.12$ \\
\hline Tegner activity score $(0-10)$ & $3.07 \pm 1.32$ & $3.28 \pm 1.32$ & $2.92 \pm 1.43$ \\
\hline Right-leg dominant $(n=22)^{\mathrm{b}}$ & $n=7(2.94 \%)$ & $n=7(2.94 \%)$ & $n=8(3.36 \%)$ \\
\hline Left-leg dominant $(n=8)^{\mathrm{b}}$ & $n=3(1.26 \%)$ & $n=2(0.84 \%)$ & $n=3(1.26 \%)$ \\
\hline Equally dominant legs $(n=12)^{\mathrm{b}}$ & $n=4(1.68 \%)$ & $n=5(2.1 \%)$ & $n=3(1.26 \%)$ \\
\hline
\end{tabular}

aside-to-side difference: (SD) of tibia anterior translation on the injured side in millimeter.

bLeg dominance and percentage of dominant and non-dominant legs in each of the three groups.

$\mathrm{ACL}$, anterior cruciate ligament; BMI, body mass index; SD, standard deviation.

Prior to the commencement of the study the principal investigator adequately trained the two involved therapists to standardize their rehabilitation procedure.

All patients were instructed to wear their functional brace and use crutches for 6 weeks during their daily activities To ensure that all patients received similar amounts of exercise, a home exercise program was not given.

After completion of the 8 weeks of ACL rehabilitation program, patients had to meet the following criteria: no pain (as indicated with a $10-\mathrm{cm}$ visual analog scale), no effusion (as measured by joint circumference), walking independently, 0- to 100-120-degree knee motion, straight leg raising in all planes, low resistance (10 reps), and multiple reps (20) with no extension lag and mini-squats 0 to 100 degrees.

\section{CEE}

The CEE program was designed based on previous studies, $^{27-29}$ as specific evidence-based guidelines for CEE on quadriceps in the early stage after ACL-reconstructed stage

Table 2 ACL Postoperative Rehabilitation Program 22,23

\begin{tabular}{|l|l|}
\hline Postoperative Phase & Rehabilitation Regimen \\
\hline Phase 1; Duration 2-4 wk & $\begin{array}{l}\text { - Immediate straight leg raising } \\
\text { - Early range of motion exercise with an emphasis on gaining } \\
\text { full knee extension (0 degrees) } \\
\text { - Weight-bearing full as tolerated } \\
\text { - First week 70-degree flexion } \\
\text { - Static squat (90-degree flexion) }\end{array}$ \\
\hline Phase 2; Duration 2-3 mo & $\begin{array}{l}\text { - Endurance training (biking) } \\
\text { - Progressive resistance training (leg press, calf press, step up) } \\
\text { - Dynamic squat (0-110 degrees) } \\
\text { - Balance exercises } \\
\text { - Eccentric muscle contractions } \\
\text { - Progressive resistance exercise full range of motion, hop on one leg without pain } \\
\text { - Isokinetic exercise and assessment }\end{array}$ \\
\hline Phase 3; Duration 3-6 mo & $\begin{array}{l}\text { - Continued progressive resistance and endurance training } \\
\text { - Jogging/running, swimming } \\
\text { - Eccentric training (active lengthening force production, such as jumping exercises) } \\
\text { - Strengthening and functional exercise training to prepare the individual for } \\
\text { full return activity } \\
\text { - Criteria for returning to full activity: } \\
\text { - 80\% strength and 85\% functional ability, proprioception }>90 \% \\
\text { - Extension/flexion strength difference }>70 \% \text { compared with the nonsurgical lower } \\
\text { extremity and Lysholm knee score }>90\end{array}$ \\
\hline Functional brace & \begin{tabular}{l}
6 wk \\
\hline
\end{tabular} \\
\hline
\end{tabular}


54 Cross-Exercise after ACL Reconstruction Papandreou et al.

Table 3 Quadriceps Strength (QS) Changes (Pre- and Postoperatively) Across the Groups

\begin{tabular}{|l|l|l|}
\hline Groups & $\uparrow$ QS\% Uninjured Knee ${ }^{\mathrm{a}}$ & $\downarrow$ QS\% Injured Knee ${ }^{\mathrm{b}}$ \\
\hline & \multicolumn{2}{|c|}{ Mean \pm SD } \\
\hline Group A (3 d/wk) & $\uparrow 22.70 \pm 20.60$ & $\downarrow 16.25 \pm 24.70$ \\
\hline Group B (5 d/wk) & $\uparrow 18.00 \pm 17.60$ & $\downarrow 6.30 \pm 26.01$ \\
\hline Group C (control) & $\uparrow 14.08 \pm 16.20$ & $\downarrow 37.83 \pm 16.90$ \\
\hline
\end{tabular}

$\mathrm{a} \uparrow \mathrm{QS} \%$, an increase of percentage in quadriceps strength.

${ }^{b} \downarrow \mathrm{QS} \%$, a decrease of percentage in quadriceps strength.

QS, quadriceps strength; QS\%, percentage quadriceps strength; SD, standard deviation.

do not exist. Cross-training was an eccentric exercise program applied on quadriceps' uninjured knee which started concurrently with the ACL physiotherapy program.

The basic exercise was one repetition maximum (1 RM) of eccentric contraction (knee extension to flexion) on the isotonic (concentric/eccentric) leg extension machine, whereas resistance was placed just above the medial malleolus. ${ }^{27,30}$

The intensity of the eccentric exercise program was submaximal $80 \%$ of $1 \mathrm{RM}$, because it has been reported to have greater strength adaptations than maximal ones. ${ }^{27,31-33}$ So, the resistance used ranged from $60.85 \pm 13.93 \mathrm{~kg}$ for the first and $61.50 \pm 11.40 \mathrm{~kg}$ for the second experimental group.

The CEE consisted of two warm up sets with no loads, following by five sets of six repetitions at $80 \%$ of 1 RM with two minutes of rest between sets. ${ }^{27,29,30}$

The first experimental group (Group A) undertook the CEE at a frequency of 3 days per week $(E 1-3 d / w)$, the second experimental group (Group B) at 5 days per week (E2-5d/w), whereas the control group (Group C) undertook only the ACL rehabilitation program.

The CEE program and the intensity were standardized throughout the 8-week period to monitor all patients, and facilitate clinical applicability of the procedure.

\section{Data Analysis}

Mean values and standard deviations were calculated for the isometric QS profile for each knee across the three groups.

One-way ANOVA was used for calculating any QS changes percentage from pre- to posttest for both, the injured and uninjured knees (pre- minus posttest/100) separately across the three groups. Post hoc analysis based on Scheffe criterion was applied to determine the location of group differences.
Two-factor ANOVA (group $\times$ time) was applied to test for group differences in QD percentage ([preoperative QS: injured - uninjured] - [postoperative QS: injured - uninjured] /100); where the group factor had three levels (Groups A, B, and C), and the time factor had two levels (pre- and postoperatively).

Body mass was used as a covariate in the analysis, as there were differences in the body weight between groups. Post hoc analysis based on Tukey HSD criterion was applied to determine the location of group differences of QD on ACL-reconstructed knees after CEE application. Results were considered statistically significant if $p$ values were less than 0.05 . All data were analyzed using SPSS software (IBM Software, Armonk, NY).

\section{Results}

QS changes from preoperatively up to 8 weeks postoperatively across the groups are shown in - Table 3. An increase of QS was evident for the uninjured knees across the groups postoperatively, in contrast to the injured knees, which demonstrated a decrease in QS for all groups (postoperatively).

Quadriceps absolute strength and percentage changes in QD between the injured and uninjured knees for the groups are shown in - Tables $\mathbf{4}$ and $\mathbf{5}$.

Changes in postoperative QD between knees were for the first experimental group (Group A) from 12.17 to $27.95 \%$, for the second (Group B) from 17.22 to $29.82 \%$, and for the control group from 24.32 to $53.00 \%$ (- Table 5).

One-way ANOVA showed that there was no significant interaction effect on QS scores in uninjured knees between the groups $(\mathrm{F}=0.781, p>0.05)$ when eccentric exercise program was conducted.

Table 4 Quadriceps Absolute Strength and Changes in QD\% between Knees Preoperatively

\begin{tabular}{|l|l|l|l|}
\hline Groups & QS Uninjured & QS Injured & $\begin{array}{c}\text { QD\% } \\
\text { Uninjured-Injured }\end{array}$ \\
\hline & \multicolumn{3}{|c|}{ Mean \pm SD } \\
\hline Group A (3 d/wk) & $437.40 \pm 178.54$ & $420.64 \pm 84.74$ & $12.17 \pm 9.30^{\mathrm{a}}$ \\
\hline Group B (5 d/wk) & $371.35 \pm 93.50$ & $315.31 \pm 91.00$ & $17.22 \pm 15.45^{\mathrm{a}}$ \\
\hline Group C (control) & $418.90 \pm 112.10$ & $354.05 \pm 127.50$ & $24.32 \pm 17.95$ \\
\hline
\end{tabular}

${ }^{\mathrm{a} S i g n i f i c a n t l y ~ l e s s ~ t h a n ~ t h e ~ c o n t r o l ~ g r o u p ~}(p<0.05)$.

QD\%, percentage quadriceps muscle strength deficit; QS, quadriceps strength; SD, standard deviation. 
Cross-Exercise after ACL Reconstruction Papandreou et al. 55

Table 5 Quadriceps Absolute Strength and Changes in QD\% between Knees, at 8 Weeks Postoperatively

\begin{tabular}{|l|l|l|l|}
\hline Groups & QS Uninjured & QS Injured & QD\% Uninjured-Injured \\
\hline & \multicolumn{3}{|c|}{ Mean \pm SD } \\
\hline Group A (3 d/wk) & $458.75 \pm 87.33$ & $344.80 \pm 135.23$ & $27.95 \pm 24.20^{\mathrm{a}}$ \\
\hline Group B (5 d/wk) & $394.00 \pm 91.20$ & $295.50 \pm 84.80$ & $29.82 \pm 21.05^{\mathrm{a}}$ \\
\hline Group C (control) & $487.95 \pm 108.33$ & $225.30 \pm 122.30$ & $53.00 \pm 24.20$ \\
\hline
\end{tabular}

aSignificantly less than the control group $(p<0.05)$.

QD\%, percentage quadriceps muscle strength deficit; QS, quadriceps strength; SD, standard deviation.

However, for the injured knees, a significant interaction effect on QS scores was evident among the groups $(\mathrm{F}=6.95$, $p<0.05$ ) following CEE. In particular, post hoc analysis determined that the significant results arose from the first experimental group compared with the control $(D=21.60$, $p=0.04)$, and from the second one compared with the control one ( $\mathrm{D}=31.60, p<0.001)$ (-Fig. 1 ).

Two-factor ANOVA showed that there was a significant interaction effect on QD percentage between groups and time ( $\mathrm{F}=5.16, p<0.001)$ after the 8 -week CEE program, on the reconstructed knees. Post hoc analysis by Tukey HSD determined that the significant results arose from both experimental groups compared with the control one (Group A: $\mathrm{D}=18.60, \quad p=0.01 ; \quad$ Group $\mathrm{B}: \mathrm{D}=15.12, \quad p=0.04)$, (-Fig. 2).

The covariate body mass did not have a confounding effect on the groups' results in the research procedure $(F=0.00$, $p=0.97, p>0.05)$.

\section{Discussion}

The purposes of this study were to investigate whether 8 weeks of a CEE program could offer more improvement or minimize quadriceps muscle strength deficit at 60 degrees of knee flexion, by either being applied at 3 or 5 times per week, in the early postoperative stage of ACL reconstruction.

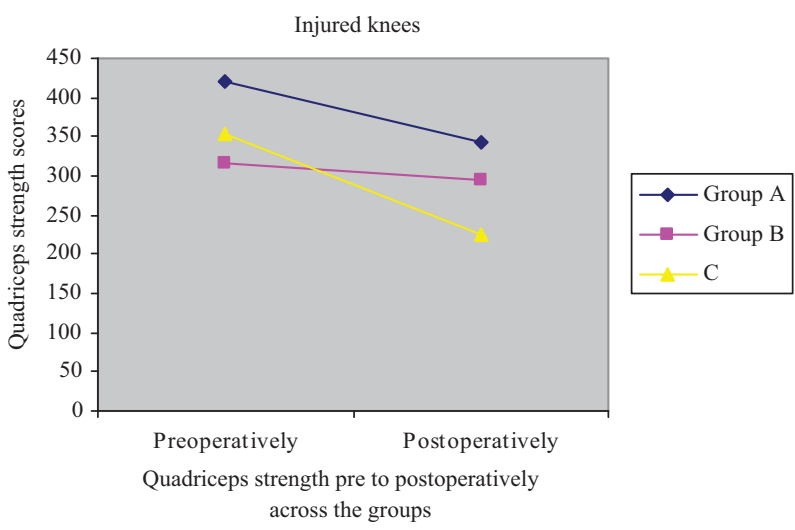

Figure 1 A significant interaction effect of contralateral-eccentric exercise (CEE) on quadriceps strength (QS) arose from Group A ( $3 \mathrm{~d} / \mathrm{wk}$ ) and Group B ( $5 \mathrm{~d} / \mathrm{wk}$ ) compared with the control one, at 8 weeks postoperatively.
The results of this study revealed changes in both knees: a strength increase of 14 to $22 \%$ for the uninjured knees across the groups, and a decrease of 6 to $16 \%$ for the two experimental groups and $37 \%$ for the control one for the injured ones; 8 weeks following the ACL reconstruction (-Table $\mathbf{3}$ ).

Evaluation of QD showed changes in percent from 12 to $24 \%$ to 27 to $53 \%$ from preoperatively to 8 weeks postoperatively for the three groups (-Table 5). Our QD values, irrespective of the supplementary CEE program performed, emphasizes that patients with ACL reconstruction in the early stage of rehabilitation showed particular interesting changes in $\mathrm{QS}$ from pre- to posttest. These results are confirmed by previous findings, where postoperative QDs have been found between 10 and $20 \%, 1,3,6,7,34,35$ despite the plethora of the progressive and accelerated exercise programs, for ACLreconstructed patients, long-term impairments often persists. $^{3,7,34,35}$

The corresponding QS values for the uninjured knee entailed increases, it would appear logical that 8 weeks of eccentric exercise program on a healthy trained limb have potential improvement. On the other hand, the status of the uninjured side may lead to misinterpretation of results due to possible bilateral neuromuscular changes after injury.

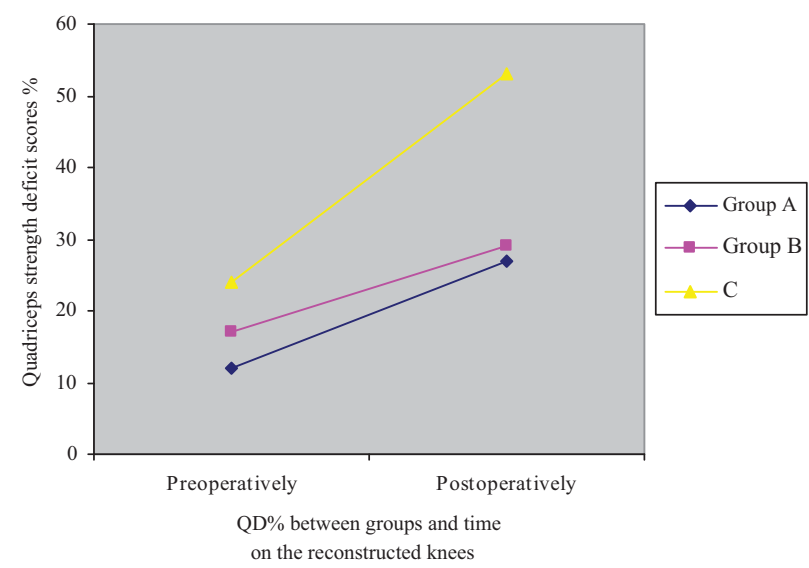

Figure 2 A significant interaction effect of CEE on quadriceps changes in quadriceps deficit (QD) percentage arose from Group A (3 d/wk) and Group B ( $5 \mathrm{~d} / \mathrm{wk}$ ) compared with the control one, at 8 weeks postoperatively. 
The results confirmed our first hypothesis that adding CEE to the traditional ACL rehabilitation program would lead to significant improvements of QD at 60 degrees of flexion in ACL-reconstructed patients. This was evident for subjects classified in experimental groups, received CEE 3 or 5 days per week. Both experimental groups showed a significantly less quadriceps muscle strength deficit compared with the control one, 8 weeks after the ACL postoperative rehabilitation phase (-Table $\mathbf{5}$ ).

This improvement on QD could be attributed to cross eccentric exercise. As far as the type of $\mathrm{CE}$ is concerned, eccentric exercise has been found to be superior to isometric or concentric exercise and seems to have the greatest effect on QS accounting for the greater increases in eccentric and isometric forces. ${ }^{31-33,36-39}$

As a consequence, our results emphasize that patients with ACL reconstruction, in the early stage of rehabilitation, have potential for clinically relevant QS improvement at 60-degree knee flexion when CEE is conducted as a supplement to the ACL traditional rehabilitation program.

ACL postoperative quadriceps muscle strength deficit have not previously been assessed using $\mathrm{CE}$ as supplementary exercise program to the traditional rehabilitation one. Limited studies have been reported on the effect of CE on patient population. It has been reported that CEE improves quadriceps muscle strength at 45- and 90-degree knee angles and quadriceps accelerated reaction time at 90 degrees of knee flexion on the ACL-reconstructed knee in the early rehabilitation stage; 8 weeks following the reconstruction. ${ }^{40,41}$ Arai et $\mathrm{al}^{42}$ investigated, in six orthopedic patients, the effect of CE on QS by applying a proprioceptive neuromuscular facilitation (PNF) exercise, at various knee angles. The PNFCE was significantly effective on QS at 60 degrees of knee flexion.

The limited amount of information for $\mathrm{QD}$ following $\mathrm{CE}$ in the early stage of ACL reconstruction should be addressed in future studies.

The second purpose of this study explored the most effective CEE frequency between the frequencies of 3 and 5 days per week (experimental groups) for the improvement of QD on the ACL-reconstructed knees.

The decision on the above frequencies was based on the notion that any exercise program must be performed for a sufficient duration of weeks and days per week to allow the muscle-specific biochemical, mitochondrial, and neurological adaptations to reach a steady state (more than 4 to 5 weeks, 3 to 5 days per week). ${ }^{43,44}$

Our 8-week CEE program combined with the ACL traditional rehabilitation program statistically minimized $Q D$ in both experimental groups compared with the control one. The results confirm previous findings that quadriceps improvements were greater for ACL-reconstructed patients who followed 3 days per week CEE rather than the control one. ${ }^{40,41}$

However, in our study no statistical results were found between the two experimental groups. From rehabilitation perspective this would appear logical that a supplementary exercise program attached to the classic rehabilitation program is more effective and is more likely to minimize QD, compared with a rehabilitation one performed alone. Whereas, no reports have implicated that a particular frequency of exercise has the greatest amount of CEE benefits on QD.

Several different training protocols designed to explore $\mathrm{CE}$ gains and adaptations comparing different kinds of exercise programs (isometric, eccentric, concentric, etc.) have been limited to the training frequency of 3 days per week. ${ }^{14,27,33,36-39}$ All the above studies used a 4- to 12 -week training program and only a limited number of studies have explored CE in patients following ACL reconstruction. ${ }^{40,41}$ Nevertheless, further research should explore different exercise frequencies in CE for this patient population.

From our findings it can be stated that it is possible to achieve significant and clinically important improvements in $\mathrm{QD}$ adding the $\mathrm{CE}$ as an adjunct rehabilitation program to the traditional ACL one, at the early phase of reconstruction.

A crucial issue when introducing progressive exercise therapy programs is the tolerance for the training load through a neural mechanism which produces the earliest activation of central nervous system. As far as the mechanism of action of CE is concerned, it is believed to be mediated by neural mechanisms including diffusion of impulses between hemispheres, coactivation via bilateral corticospinal pathways, postural stabilization, and the cerebral cortex theory. ${ }^{14}$ This latter theory has been referred to as the most dominant mechanism acting via the voluntary contraction of a specific muscle-on the trained side-and then a facilitation effect is produced at the same motor point in the opposite side via the cerebral cortex. . $^{28,29,45}$

Future randomized controlled trials including treatment groups with larger sample sizes testing different frequencies of CE programs are needed to verify the potential effectiveness of this proposed program.

\section{Limitations}

Although, an assessment of which was the dominant limb was provided, due to the study design and to our small sample we did not determine the effectiveness of CEE after the ACL reconstruction for the dominant and nondominant limbs. Future studies are needed to clarify this issue.

During the 8 weeks of CEE we did not monitor the training velocity between the two experimental groups, and did not change the mode of the program. On the other hand, it does not seem to be an obvious relationship across studies between the mode of exercise program (training velocity, intensity, duration) and the magnitude of $\mathrm{CE} .^{14}$

However, the training procedures employed in the study supported a clinically applicable and practical approach, though; no exercise progression throughout the training period was provided.

However, as no previous studies have measured CEE in specific contraction velocities or exercise modes, it felt logical to start with a nonprogressive standard exercise for first establishing its effectiveness in ACL patients.

Finally, we did not determine the long-term effects of CEE following the ACL reconstruction. Thus, further research is required on this concept. 


\section{Conclusion}

This study demonstrated that CEE used as supplementary to the ACL traditional rehabilitation program in the early stages of reconstruction improves quadriceps muscle strength deficit.

CEE at the frequencies of 3 or 5 days per week significantly minimized QD compared with a control group which did not receive $\mathrm{CEE}$ following the $\mathrm{ACL}$ reconstruction. Further research should be conducted to investigate the long-term effects of $C E$ in ACL reconstruction rehabilitation management.

\section{References}

1 McHugh MP, Tyler TF, Browne MG, Gleim GW, Nicholas SJ. Electromyographic predictors of residual quadriceps muscle weakness after anterior cruciate ligament reconstruction. Am J Sports Med 2002;30(3):334-339

2 Konishi Y, Fukubayashi T, Takeshita D. Possible mechanism of quadriceps femoris weakness in patients with ruptured anterior cruciate ligament. Med Sci Sports Exerc 2002;34(9):1414-1418

3 Snyder-Mackler L, De Luca PF, Williams PR, Eastlack ME, Bartolozzi AR III. Reflex inhibition of the quadriceps femoris muscle after injury or reconstruction of the anterior cruciate ligament. J Bone Joint Surg Am 1994;76(4):555-560

4 Urbach D, Nebelung W, Weiler HT, Awiszus F. Bilateral deficit of voluntary quadriceps muscle activation after unilateral ACL tear. Med Sci Sports Exerc 1999;31(12):1691-1696

5 Kim KM, Croy T, Hertel J, Saliba S. Effects of neuromuscular electrical stimulation after anterior cruciate ligament reconstruction on quadriceps strength, function, and patient-oriented outcomes: a systematic review. J Orthop Sports Phys Ther 2010;40 (7):383-391

6 Eitzen I, Moksnes H, Snyder-Mackler L, Risberg MA. A progressive 5-week exercise therapy program leads to significant improvement in knee function early after anterior cruciate ligament injury. J Orthop Sports Phys Ther 2010;40(11):705-721

7 Arangio GA, Chen C, Kalady M, Reed JF III. Thigh muscle size and strength after anterior cruciate ligament reconstruction and rehabilitation. J Orthop Sports Phys Ther 1997;26(5):238-243

8 Aune AK, Cawley PW, Ekeland A. Quadriceps muscle contraction protects the anterior cruciate ligament during anterior tibial translation. Am J Sports Med 1997;25(2):187-190

9 Dürselen L, Claes L, Kiefer H. The influence of muscle forces and external loads on cruciate ligament strain. Am J Sports Med 1995;23(1):129-136

10 Dienst M, Burks RT, Greis PE. Anatomy and biomechanics of the anterior cruciate ligament. Orthop Clin North Am 2002;33(4): 605-620, v

11 Li G, Rudy TW, Sakane M, Kanamori A, Ma CB, Woo SL. The importance of quadriceps and hamstring muscle loading on knee kinematics and in-situ forces in the ACL. J Biomech 1999;32(4):395-400

12 Suter E, Herzog W. Extent of muscle inhibition as a function of knee angle. J Electromyogr Kinesiol 1997;7(2):123-130

13 Itoh H, Ichihashi N, Maruyama T, Kurosaka M, Hirohata K. Weakness of thigh muscles in individuals sustaining anterior cruciate ligament injury. Kobe J Med Sci 1992;38(2):93-107

14 Zhou S. Chronic neural adaptations to unilateral exercise: mechanisms of cross education. Exerc Sport Sci Rev 2000;28(4):177-184

15 Wasilewski SA, Covall DJ, Cohen S. Effect of surgical timing on recovery and associated injuries after anterior cruciate ligament reconstruction. Am J Sports Med 1993;21(3):338-342

16 Shelbourne KD, Foulk DA. Timing of surgery in acute anterior cruciate ligament tears on the return of quadriceps muscle strength after reconstruction using an autogenous patellar tendon graft. Am J Sports Med 1995;23(6):686-689

17 Internatinal Knee Documentation CommitteeIKDC Knee Examination Forms. Available at: http://www.sportsmed.org/rereasch/ IKDC.asp. Accessed 2000

18 Tegner Y, Lysholm J. Rating systems in the evaluation of knee ligament injuries. Clin Orthop Relat Res 1985;198:43-49

19 Karlson JA, Steiner ME, Brown CH, Johnston J. Anterior cruciate ligament reconstruction using gracilis and semitendinodus tendons. J Orthop Sports Phys Ther 1994;22:659-666

20 Coren S, Porac C. The validity and reliability of self-report items for the measure of lateral preference. Br J Psychol 1978;69:207-211

21 Elias LJ, Bryden MP, Bulman-Fleming MB. Footedness is a better predictor than is handedness of emotional lateralization. Neuropsychologia 1998;36(1):37-43

22 Wilk KE, Reinold MM, Hooks TR. Recent advances in the rehabilitation of isolated and combined anterior cruciate ligament injuries. Orthop Clin North Am 2003;34(1):107-137

23 Majima T, Yasuda K, Tago H, Tanabe Y, Minami A. Rehabilitation after hamstring anterior cruciate ligament reconstruction. Clin Orthop Relat Res 2002;397:370-380

24 Beynnon BD, Fleming BC, Johnson RJ, Nichols CE, Renström PA, Pope MH. Anterior cruciate ligament strain behavior during rehabilitation exercises in vivo. Am J Sports Med 1995;23(1):24-34

25 Keays SL, Bullock-Saxton J, Keays AC. Strength and function before and after anterior cruciate ligament reconstruction. Clin Orthop Relat Res 2000;373:174-183

26 Keays SL, Bullock-Saxton JE, Keays AC, Newcombe PA, Bullock MI. A 6-year follow-up of the effect of graft site on strength, stability, range of motion, function, and joint degeneration after anterior cruciate ligament reconstruction: patellar tendon versus semitendinosus and gracilis tendon graft. Am J Sports Med 2007;35(5): 729-739

27 Housh TJ, Housh DJ, Weir JP, Weir LL. Effects of eccentric-only resistance training and detraining. Int J Sports Med 1996;17(2): 145-148

28 Herbert RD, Gandevia SC. Muscle activation in unilateral and bilateral efforts assessed by motor nerve and cortical stimulation. J Appl Physiol 1996;80(4):1351-1356

29 Howard JD, Enoka RM. Maximum bilateral contractions are modified by neurally mediated interlimb effects. J Appl Physiol 1991;70 (1):306-316

30 LaStayo PC, Woolf JM, Lewek MD, Snyder-Mackler L, Reich T, Lindstedt SL. Eccentric muscle contractions: their contribution to injury, prevention, rehabilitation, and sport. J Orthop Sports Phys Ther 2003;33(10):557-571

31 Hortobágyi T, Barrier J, Beard D, et al. Greater initial adaptations to submaximal muscle lengthening than maximal shortening. J Appl Physiol 1996;81(4):1677-1682

32 Hortobágyi T, Hill JP, Houmard JA, Fraser DD, Lambert NJ, Israel RG. Adaptive responses to muscle lengthening and shortening in humans. J Appl Physiol 1996;80(3):765-772

33 Hortobágyi T, Lambert NJ, Hill JP. Greater cross education following training with muscle lengthening than shortening. Med Sci Sports Exerc 1997;29(1):107-112

34 Keays SL, Bullock-Saxton JE, Newcombe P, Keays AC. The relationship between knee strength and functional stability before and after anterior cruciate ligament reconstruction. J Orthop Res 2003;21(2):231-237

35 Risberg MA, Holm I, Tjomsland O, Ljunggren E, Ekeland A. Prospective study of changes in impairments and disabilities after anterior cruciate ligament reconstruction. J Orthop Sports Phys Ther 1999;29(7):400-412

36 Weir JP, Housh DJ, Housh TJ, Weir LL. The effect of unilateral eccentric weight training and detraining on joint angle specificity, cross-training, and the bilateral deficit. J Orthop Sports Phys Ther 1995;22(5):207-215 
37 Kannus P, Alosa D, Cook L, et al. Effect of one-legged exercise on the strength, power and endurance of the contralateral leg. A randomized, controlled study using isometric and concentric isokinetic training. Eur J Appl Physiol Occup Physiol 1992;64(2): 117-126

38 Weir JP, Housh DJ, Housh TJ, Weir LL. The effect of unilateral concentric weight training and detraining on joint angle specificity, cross-training, and the bilateral deficit. J Orthop Sports Phys Ther 1997;25(4):264-270

39 Taniguchi Y. Lateral specificity in resistance training: the effect of bilateral and unilateral training. Eur J Appl Physiol Occup Physiol 1997;75(2):144-150

40 Papandreou MG, Papaioannou N, Antonogiannakis E, et al. The effect of cross exercise on quadriceps strength in different knee angles after the anterior cruciate ligament reconstruction. Braz J Biomotricity 2007;1(4):123-138

41 Papandreou MG, Billis EV, Antonogiannakis EM, Papaioannou NA. Effect of cross exercise on quadriceps acceleration reaction time and subjective scores (Lysholm questionnaire) following anterior cruciate ligament reconstruction. J Orthop Surg 2009;4:2

42 Arai M, Shimizu H, Shimizu ME, Tanaka Y, Yanagisawa K. Effects of the use of cross-education to the affected side through various resistive exercises of the sound side and settings of the length of the affected muscles. Hiroshima J Med Sci 2001;50(3): 65-73

43 Position Stand ACSM. American College of Sports Medicine Position Stand. The recommended quantity and quality of exercise for developing and maintaining cardiorespiratory and muscular fitness, and flexibility in healthy adults. Med Sci Sports Exerc 1998;30(6):975-991

44 Morrissey MC, Harman EA, Johnson MJ. Resistance training modes: specificity and effectiveness. Med Sci Sports Exerc 1995;27(5): 648-660

45 Carr LJ, Harrison LM, Stephens JA. Evidence for bilateral innervation of certain homologous motoneurone pools in man. J Physiol 1994;475(2):217-227 